\title{
A Pedagogia de Projetos na compreensão das CONSEQUENCIAS SOCIOAMBIENTAIS DE ACIDENTES COM BARRAGENS
}

\author{
The PROJECTS PEDAGOGY IN UNDERSTANDING THE SOCIAL AND \\ ENVIRONMENTAL CONSEQUENCES OF ACCIDENTS WITH DAMS
}

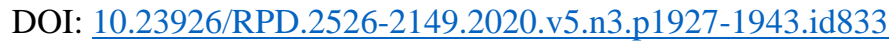

\section{Carmem Lúcia Costa Amaral \\ Doutora em Ciências (USP) \\ Professora pesquisadora da \\ UNICSUL \\ carmem.amaral@cruzeirodos ul.edu.br}

Tatiane Baldoria

Mestre em Ensino de Ciência (UNICSUL)

Professora da ETEC baldoriat@gmail.com
Resumo: O rompimento de barragens que ocorreram no Brasil nos últimos anos provocou impactos ambientais irreparáveis que não podem passar despercebidos. Nesse contexto, torna-se importante discutir na escola as consequências socioambientais provocadas por esses acidentes. Nesse artigo apresenta-se uma prática pedagógica envolvendo a pedagogia de projetos que teve como objetivo investigar sua contribuição na compreensão dessas consequências. A metodologia utilizada foi a pesquisa qualitativa. Participaram dessa prática 75 alunos do Ensino Médio Integrado ao Técnico em Edificações. Os alunos foram divididos em grupos e desenvolveram seus projetos tendo como referência as etapas propostas por Nogueira (2008). O processo avaliativo foi processual e diagnóstico, ou seja, perpassou todas as etapas do projeto. Os resultados dessa avaliação evidenciaram que a pedagogia de projetos contribuiu não só para a compreensão dos impactos socioambientais dos acidentes envolvendo barragens, mas também desenvolveu autonomia e contribuiu para a construção de conhecimento para tratar dessa temática.

Palavras-chave: Pedagogia de Projetos. Ensino Técnico. Acidentes com Barragens.

\begin{abstract}
The dam's rupture occurred in Brazil in previous years caused irreparable environmental impacts that cannot undergo unnoticed. In this context, it become important to discuss in the school the socio environmental consequences caused by those accidents. In this paper it is presented a pedagogical practice involving the project's pedagogy that had as an objective explore its contributions in the comprehension of those consequences. 75 students from the High School integrated to the Buildings Technical School participated in this practice. The students were divided into groups and developed their projects having as reference the steps presented by Nogueira (2008). The evaluation process was procedural and diagnostical, that is, passed through all the project's steps. The results of this evaluation pointed that the project's pedagogy contributes not only to the comprehension of the social and environmental impacts of the accidents involving dams, but also developed autonomy and knowledges to address this theme.
\end{abstract}

Keywords: Pedagogy Project. Environmental Accidents. Dam Accidents. 


\section{INTRODUÇÃo}

\section{Introdução}

O técnico em edificações é um profissional do setor da construção civil e uma de suas atribuições é o cuidado com o meio ambiente, pois de acordo com Castanheira et al. (2016) a indústria da construção civil é um dos setores que mais consome recursos naturais, gerando consideráveis impactos ambientais. Assim, durante sua formação é importante despertar no futuro técnico um olhar diferenciado para o meio ambiente e uma forma de fazer isso é o professor partir de situações reais, pois como descrevem Paula e Henrique (2016, p. 90) "trabalhar situações reais é imprescindível para que os sujeitos se percebam parte do meio e sintam-se por ele responsáveis".

A situação real que será apresentada nesse artigo são os acidentes com barragens e para isso foi utilizada a pedagogia de projetos, que como definem Cunha e Oliveira (2019) é uma metodologia de ensino onde se utilizam atividades organizadas, com o intuito de resolver uma problemática que envolve o cotidiano dos alunos. Ao realizar um projeto o aluno torna-se protagonista da construção do seu conhecimento, contextualizando conceitos, desenvolvendo a criticidade, a autonomia e despendendo da temática, a sensibilização quanto as questões ambientais, que vão auxiliá-lo em sua vida acadêmica e profissional como técnico.

Os acidentes com barragens como apontam Fontes e Lopes (2017), muitas vezes, não são conhecidas pela maioria da população brasileira porque não tem grande repercussão nas mídias. Somente aqueles envolvendo um número considerável de vítimas são de interesse midiático, por exemplo, os que ocorreram no Estado de Minas Gerais na cidade de Mariana, em 2015 e em Brumadinho, em 2019.

De acordo com Fonseca (2019), no Brasil há em média mais de três acidentes com barragens a cada ano, alguns incluem o rompimento de grandes barragens com vítimas fatais, como as citadas acima e outros incluem eventos menores (incidentes) que provocam alagamentos ou suspensão do abastecimento de água. No período de 2011 a 2017, segundo o autor, ocorreram 52 incidentes com barragens.

Como pode-se perceber essa é uma situação preocupante e deve ser discutida na escola, principalmente, em um curso técnico em edificações, uma vez que esse técnico pode fazer parte da equipe responsável pela manutenção e construção de barragens. Além disso como apontam Silva, Batista e Silva (2017) no ensino técnico, em geral, o aluno direciona os seus estudos para 
temas relacionados ao trabalho, visando o mercado de trabalho, e como consequência os valores humanos e ambientais são deixados de lado. Assim, a realização de pesquisa em sala de aula propicia espaço para que os alunos desenvolvam valores e competências para intervir nas transformações sociais e ambientais no contexto em que vivem.

Nesse trabalho, apresenta-se o resultado de uma prática pedagógica envolvendo a pedagogia de projetos que teve como objetivo investigar sua contribuição na compreensão das consequências socioambientais de acidentes envolvendo barragens. Os alunos desenvolveram seus projetos tendo como referência as etapas propostas por Nogueira (2008). O processo avaliativo dos alunos foi processual e diagnóstico, ou seja, perpassou todas as etapas do projeto. Quanto a avaliação da pedagogia de projetos foi utilizado o modelo proposto por Cohen e Lotan (2017).

O texto apresenta alguns apontamentos sobre a pedagogia de projetos, como essa metodologia foi aplicada na escola dentro de uma prática da pesquisa qualitativa e os resultados observados durante e após o seu desenvolvimento pelos alunos.

\section{A PEDAgOGIA DE PROJETOS}

A pedagogia de projetos iniciou-se na Europa no início do século XX com os estudos de John Dewey que defendia a ideia de que a criança vai para a escola para resolver os problemas enfrentados em seu dia-a-dia e que a escola para auxiliá-la a pensar, deveria proporcionar no ambiente escolar, atividades que pudessem desenvolver a capacidade de resolução de problemas. A partir de suas ideias, William Heard Kilpatrick (1871- 1965) sistematizou o método de projetos (OLIVEIRA; GONZAGA, 2009).

O método de projetos de Kilpatrick, desde sua origem, recebeu várias denominações tais como projetos de trabalho, metodologia de projetos, metodologia de aprendizagem por projetos e pedagogia de projetos. Nesse artigo será utilizada a denominação pedagogia de projetos.

A discussão em torno da pedagogia de projetos teve início no Brasil na década de 1930 com Anísio Teixeira e Lourenço Filho, ambos idealistas da Escola Nova. Desde então, o movimento tem sido reinterpretado por diversos autores, entre eles, Nogueira (2008) que a considera uma metodologia que propicia a interação sujeito-objeto de conhecimento e torna o aluno protagonista do seu conhecimento e consequentemente motiva-o a aprender. 
Para Cohen e Lotan (2017), esse tipo de metodologia é eficaz para atingir aprendizagem intelectual, conceitual e social, aumentando com isso a oportunidade do aluno aprender conteúdos de maneira aprofundada e diversificada.

Com a pedagogia de projetos os alunos partem dos seus conhecimentos prévios sobre a temática da pesquisa, ampliando-os, uma vez que utilizarão diversas fontes de informações conectando diferentes campos de conhecimento (SILVA, 2011).

Para Santos e Leal (2018) a pedagogia de projetos propicia a aprendizagem significativa, uma vez que o aluno interage com outros no desenvolvimento do seu projeto e essa interação leva-o a uma experiência em que o processo de construção de conhecimento não só está relacionado às práticas de vida, mas confunde-se ou é a própria vida dentro e fora do âmbito escolar. Como descreve Antunes (2012) realizar projetos com os alunos somente se justifica quando eles colocam seu interesse e sua energia na busca de temas que lhes sejam relevantes e essenciais para a aprendizagem no programa da disciplina. Para isso é importante que o tema do projeto parta do interesse dos alunos.

Para Guedes et al. (2017) trabalhar com projetos auxilia na formação de indivíduos capazes de atuarem na sociedade de maneira participativa, crítica, reflexiva, autônoma e solidária, além de contribui não só para a vida escolar como também para a vida social do aluno.

Assim, as funções de um projeto são favorecer a organização dos conhecimentos escolares em relação ao tratamento da informação; facilitar a relação entre os diferentes conteúdos em torno de problemas ou hipóteses que auxiliam os alunos na construção de seus conhecimentos, favorecer a transformação da informação procedente dos diferentes saberes disciplinares em conhecimento próprio (HERNANDEZ; VENTURA, 1998).

Essas funções contribuem para a valorização do aluno e são caminhos a serem percorridos de forma promissora para que seja possível a aplicação do conhecimento escolar na resolução de problemas reais (PINHEIRO, 2016). Entre esses problemas reais estão os acidentes ambientais.

Entretanto, não se pode esquecer do papel do professor que é essencialmente o de orientar os alunos a estruturar o percurso do projeto e a produzir o conhecimento de maneira contextualizada, partindo dos seus conhecimentos prévios. O professor para auxiliar o aluno quanto ao percurso do projeto deve conhecer as suas diferentes etapas que variam de acordo com os autores. Por exemplo, para Hernandez e Ventura (1998) essas etapas são problematização, seleção da bibliografia, sistematização, produção e por último, a divulgação dos resultados. Para Martins (2001) são problematização, desenvolvimento e síntese ou 
conclusão e para Nogueira (2008) são planejamento, montagem e execução, depuração e ensaio, apresentação e, por último, avaliação e críticas. Para o desenvolvimento desse artigo foram utilizadas as etapas definidas por Nogueira.

Como pode ser observado nessas etapas, a pedagogia de projetos é uma metodologia de ensino com base em atividades organizadas e a partir dessa organização o aluno chega a resolução de uma problemática que envolve o seu cotidiano, aproximando a teoria da realidade vivenciada por ele (CUNHA; OLIVEIRA, 2019).

A etapa de planejamento de acordo com Nogueira (2008), é o momento de planejar, estruturar mesmo que mentalmente o que será realizado no projeto para direcionar suas etapas. A partir do planejamento os alunos deverão ter autonomia para executarem suas ações. O professor deve controlar o planejamento estimulando-os a realizarem diversos questionamentos. Quanto mais questões forem formuladas, melhor será o planejamento. Para esse autor, o aluno deve ter em mente respostas para perguntas como: "Sobre o que falaremos/ pesquisaremos? Quais serão os objetivos? Como apresentaremos este projeto?” (p.42).

Para Nogueira (2008) responder essas perguntas é importante para que o aluno se sinta responsável pelo projeto, pois é importante que ele perceba que o projeto é dele e que o maior beneficiado com as descobertas e com as produções será ele próprio. Ao planejar seu projeto é necessário que os alunos participem mais intensamente na resolução das atividades e no processo de aprendizagem, não se limitando a copiar ou a reproduzir instruções dos professores.

A etapa de execução, como relata Nogueira (2008) é a do "realizar", em que múltiplas interações acontecem, em que o planejado na fase anterior é colocado em execução. Esta é uma fase de extrema importância para os alunos, pois irão demonstrar suas habilidades e romper a passividade diante dos problemas a serem resolvidos.

Para esta etapa o papel do professor é de facilitador, pois é ele quem irá auxiliar os alunos na escolha dos materiais necessários para execução do projeto e buscar soluções para os problemas iniciais. É necessário também que o professor questione sempre sobre o que farão com as informações, pois é nessa etapa que eles irão classificar, depurar e utilizar seus dados para transformar informação em conhecimento (NOGUEIRA, 2008).

A etapa seguinte do projeto é a depuração que consiste em analisar e refletir sobre tudo o que foi elaborado na execução. Para essa fase o professor deve questionar o aluno sobre o que produziu, sua satisfação em relação ao projeto, o que faltou ou algo que foi desnecessário.

Essa é uma etapa que deve ser realizada concomitantemente com a de execução, pois ela não é estanque e não ocorre ao mesmo tempo para cada aluno. Nessa etapa, os alunos devem 
entender que eles podem replanejar, reelaborar, reproduzir, criar hipóteses, mudar percursos, alterar rotas ou processos, pois o projeto não deve ser engessado. Quando o professor perceber que os alunos estão prontos, satisfeitos com o que produziram devem então seguir para a apresentação (NOGUEIRA, 2008).

$\mathrm{Na}$ etapa de apresentação, o professor realiza a avaliação das aquisições, enquanto o aluno expõe tudo aquilo que aprendeu ou descobriu da temática em questão. Essa etapa dará a ele a oportunidade de expor suas descobertas, hipóteses, criação e conclusões. Para isso é necessário que esteja preparado para demonstrar o aprofundamento do conhecimento sobre o assunto. Essa apresentação pode ser de diversas maneiras, como feiras, teatro, canto, dança etc. Terminadas as apresentações é necessário reunir os alunos para a próxima etapa que é a avaliação.

A avaliação pode ser do projeto desenvolvido, autoavaliação da aprendizagem dos conhecimentos ou da aplicação da pedagogia de projeto. Nesse trabalho foi realizada a avaliação processual e diagnóstica dos alunos e também da aplicação da pedagogia de projetos. Na etapa de avaliação do projeto segundo Nogueira (2008), não se deve avaliar o que o aluno sentiu com o projeto, se gostou ou não por exemplo, mas sim, se os seus objetivos foram alcançados e como foram alcançados, ou seja, como elaborou, avaliando assim, todas as etapas que planejou.

Quanto a avaliação da aplicação da metodologia Cohen e Lotan (2017) descrevem que seu propósito é elevar o potencial acadêmico, reduzir as disparidades entre grupos étnicos e de diferentes classes sociais, e melhorar a interação entre os alunos, desatrelando a aprendizagem das atividades as notas e menções.

Essa interação citada acima pelos autores ocorre porque, em geral, os projetos são desenvolvidos por grupos de alunos, é um trabalho de equipe que amplia as relações sociais. Além disso, Bender (2014) diz que o trabalho em equipe é uma maneira das escolas aumentarem o nível de desempenho e envolvimento dos alunos. Grupos de quatro ou cinco alunos parecem ser ideais para discussões produtivas e colaboração eficiente.

A pedagogia de projetos melhora as relações sociais e de acordo com Parolin et al. (2006), os professores que a adotam, auxiliam o aluno não só na construção do seu conhecimento, mas também quando este adentra no mundo do trabalho, uma vez que o mercado busca pessoas que saibam trabalhar em equipe, que sejam ousadas, criativas, inovadoras, empreendedoras e desenvolvam ações que agilizem, favoreçam e melhorem o mundo em que vivemos, em particular, em relação as questões ambientais que hoje não podem deixar de ser 
discutidas em sala de aula, pois compromete não só a geração atual, mas também as gerações futuras.

Esse comprometimento envolve a extração de recursos naturais que nem sempre são renováveis e quando consumidos de forma não planejada pode acarretar problemas ambientais irreversíveis ao planeta. Deste modo, todos devem buscar ações e estratégias para minimizar esses problemas e a comunidade escolar não pode ficar por fora, em particular a comunidade que ensina em cursos técnicos em edificações, uma vez que entre os conhecimentos que esse profissional não pode deixar de contemplar estão os que envolvem as questões ambientais, entre elas, as consequências socioambientais de acidentes com barragens, pois esse técnico, junto com o engenheiro, pode ser o responsável pela sua construção e fiscalização.

Como todos tem conhecimento, o rompimento da barragem do Fundão em Mariana (MG) é considerado o maior acidente ambiental envolvendo mineração no mundo, com 19 vítimas fatais e mais de 300.000 afetadas direta ou indiretamente.

Em 25 de janeiro de 2019 aconteceu outro acidente com barragem na cidade de Brumadinho (MG) que despejou 12 milhões de $\mathrm{m}^{3}$ de rejeitos sobre a cidade, porém desta vez, o número de vítimas chegou a 278 e 11 desaparecidos (CONECTAS, 2020). Em janeiro de 2020, os moradores de uma comunidade na cidade de Alegre (ES) tiveram que deixar suas casas devido ao risco de rompimento de mais uma barragem devido a elevação do nível de águas em função das chuvas que atingiram a região (AGÊNCIA BRASIL, 2020).

Esses acontecimentos remetem a reflexão sobre a falta de fiscalização e manutenção de barragens que é um problema de políticas públicas e que deve ser discutido nas escolas, principalmente com alunos do técnico em edificações.

\section{Metodologia}

Esse estudo se caracteriza como uma pesquisa qualitativa que de acordo com Coutinho (2013, p.28) “descreve os fenômenos por palavras em vez de número ou medidas”. Assim, o processo avaliativo foi processual e diagnóstico, ou seja, perpassou todas as etapas do projeto.

Participaram desse estudo 75 alunos do $1^{0}$ ano do Ensino Médio Integrado ao Técnico de Edificações de uma Escola Técnica Estadual (ETEC) localizada na zona leste da cidade de São Paulo. Os alunos tinham idade entre 14 e 17 anos e cursavam a disciplina de Química que faz parte da Base Nacional Curricular desse nível de ensino. O Quadro 1 apresenta as atividades desenvolvidas nas fases da pedagogia de projetos. 
Quadro 1 - Atividades desenvolvidas em cada etapa do projeto e a quantidade de aulas utilizadas

\begin{tabular}{|l|l|c|}
\hline \multicolumn{1}{|c|}{ Etapas do Projeto } & \multicolumn{1}{|c|}{ Atividade } & $\begin{array}{c}\text { Quantidade de } \\
\text { aula }\end{array}$ \\
\hline Planejamento & $\begin{array}{l}\text { Aula dialogada sobre acidentes ambientais com barragens. } \\
\text { Distribuição de tópicos por grupo. }\end{array}$ & 2 aulas \\
\hline Montagem/ execução & $\begin{array}{l}\text { Reprodução de vídeos sobre o acidente com a barragem na } \\
\text { cidade de Mariana disponíveis em: } \\
\text { https://www.youtube.com/watch?v=QJTBe3LwKvY\&t=8s } \\
\text { https://www.youtube.com/watch?v=DvprawvqQgs }\end{array}$ & 2 aulas \\
\hline Montagem e execução & $\begin{array}{l}\text { Aulas no laboratório de informática. } \\
\text { Orientação para finalização dos projetos dos alunos }\end{array}$ & 2 aulas \\
\hline Depuração e Ensaio & Reflexão sobre a montagem do projeto pelos alunos. & 2 aulas \\
\hline $\begin{array}{l}\text { Apresentação e } \\
\text { Avaliação }\end{array}$ & $\begin{array}{l}\text { Apresentação para os demais alunos da instituição. } \\
\text { Avaliação dos projetos pelos alunos da escola } \\
\text { Avaliação da pedagogia de Projetos }\end{array}$ & \multicolumn{1}{|c|}{2 aulas } \\
\hline
\end{tabular}

Fonte: As autoras.

Na primeira fase da pedagogia de projetos, planejamento, todos assistiram dois vídeos que estão disponíveis no YouTube e leram o artigo do Carvalho et al. (2017). Os vídeos discutem as causas e as consequências de acidente com a barragem que ocorreu na cidade de Mariana e o artigo descreve sobre a contaminação de metais pesados nos rios devido a esses acidentes.

Após a exibição dos vídeos e a leitura do artigo foi realizada uma discussão sobre os tópicos apresentados e em seguida foi solicitado que todos definissem o objetivo do seu projeto e como apresentá-los. Todos decidiram analisar o papel do técnico de edificações nos acidentes ambientais, mas, de acordo com eles, precisavam conhecer a história da mineração e de construção de barragens.

Após essa decisão os alunos se organizaram em grupos de 5 a 7 componentes e decidiram realizar seus projetos a partir de uma linha do tempo em que seria contada a história da cidade de Mariana, o início da mineração na cidade, a instalação da empresa responsável pela construção das barragem, o rompimento da barragem e uma possível recuperação do vilarejo afetado (Quadro 2). 
Quadro 2 - Definição dos tópicos do projeto dos alunos.

\begin{tabular}{|c|c|}
\hline Grupos & Tópicos escolhidos \\
\hline 1 & História da Mineração \\
\hline 2 & Processo de Extração de Metais \\
\hline 3 & Impactos Ambientais sob a Extração de Minérios \\
\hline 4 & História da Cidade de Mariana \\
\hline 5 & Implantação da Samarco-Criação da Barragem \\
\hline 6 & Rompimento da Barragem do Fundão (o acidente e as causas) \\
\hline 7 & Impactos Ambientais e Socioeconômicos do Rompimento \\
\hline 8 & Possível Solução de Reconstrução para a Barragem e para os Vilarejos. \\
\hline
\end{tabular}

Fonte: As autoras.

Para a fase de apresentação, os grupos organizaram um workshop no pátio da escola e nesse momento os colegas de outras classes analisaram seus projetos a partir da ficha apresentada no Quadro 3.

Quadro 3 - Ficha de avaliação dos projetos dos alunos no workshop

\begin{tabular}{|l|l|l|l|l|}
\hline \multicolumn{1}{|c|}{$\begin{array}{c}\text { Critérios de avaliação da } \\
\text { apresentação }\end{array}$} & Pleno & Bom & Satisfatório & Insatisfatório \\
\hline Argumentação consistente & & & & \\
\hline Clareza na apresentação & & & & \\
\hline Comunicação & & & & \\
\hline Postura & & & & \\
\hline Objetividade & & & & \\
\hline $\begin{array}{l}\text { Participação dos membros do grupo } \\
\text { de apresentação }\end{array}$ & & & & \\
\hline $\begin{array}{l}\text { Integração entre os membros do } \\
\text { grupo }\end{array}$ & & & & \\
\hline
\end{tabular}

Fonte: As autoras.

Para a análise da pedagogia de projetos foi utilizado o modelo de avaliação proposto por Cohen e Lotan (2017) que está apresentado no Quadro 4.

\section{Quadro 4 -}


Quadro 4 - Questionário para avaliação da Pedagogia de Projetos pelos alunos

\begin{tabular}{|c|c|}
\hline $\begin{array}{l}\text { 1.Qual o seu nivel de } \\
\text { interesse pelo trabalho } \\
\text { realizado? }\end{array}$ & $\begin{array}{l}\text { (1) Muito interessante ( ) Razoavelmente interessante } \\
1) \text { Um pouco interessante ( ) Não muito interessante } \\
(1) \text { Nem um pouco interessante }\end{array}$ \\
\hline $\begin{array}{l}\text { 2.Qual o nivel de dificuldade } \\
\text { encontrado no } \\
\text { desenvolvimento do projeto? }\end{array}$ & $\begin{array}{l}(1) \text { Extremamente difícil ( ) Razoavelmente difícil } \\
\square \text { Às vezes difícil } \\
(1) \text { Não muito difícil - apenas o suficiente } \\
\square \text { Muito fácil }\end{array}$ \\
\hline $\begin{array}{l}\text { 3.Você entendeu exatamente } \\
\text { a proposta do projeto? }\end{array}$ & $\begin{array}{l}\qquad \text { Sabia exatamente o que fazer } \\
(1) \text { No início eu não tinha entendido } \\
\square \text { Nunca ficou claro para mim }\end{array}$ \\
\hline $\begin{array}{l}\text { 4.Se você participou menos } \\
\text { do que gostaria neste } \\
\text { trabalho, quais foram as } \\
\text { principais razōes para isso? }\end{array}$ & 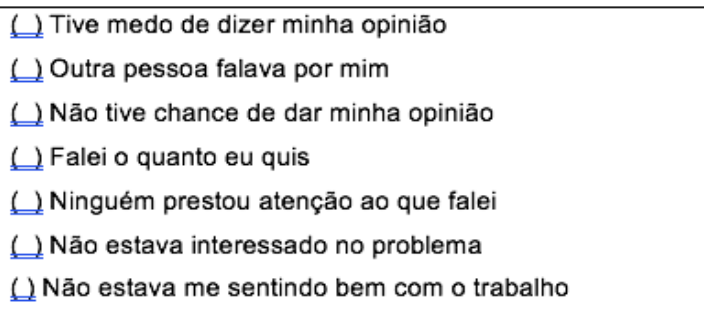 \\
\hline $\begin{array}{l}\text { 5.Você se entendeu bem } \\
\text { como todos do seu grupo? }\end{array}$ & $\begin{array}{l}\qquad \text { Com alguns deles ( ) Com metade deles } \\
\square \text { Com a maioria deles ( ) Com todos eles } \\
\square \text { Com nenhum deles }\end{array}$ \\
\hline $\begin{array}{l}\text { 6.Quantos integrantes do } \\
\text { grupo escutaram suas ideias } \\
\text { e as dos outros colegas? }\end{array}$ & $\begin{array}{l}\square \text { Poucos ( ) Metade deles } \\
\square \text { A maioria deles } \\
\square \text { Todos eles, exceto um } \\
\square \text { Todos eles }\end{array}$ \\
\hline $\begin{array}{l}\text { 7.Você gostaria de trabalhar } \\
\text { com projetos novamente? }\end{array}$ & $\begin{array}{l}\Longleftrightarrow \operatorname{Sim} \\
\biguplus \text { Não }\end{array}$ \\
\hline
\end{tabular}

Fonte: Cohen e Lotan (2017) adaptado.

\section{Resultados E Discussão}

Após a etapa de planejamento e a escolha dos seus projetos, os grupos se organizaram e planejaram como realizar as pesquisas (Etapa de montagem e execução). Todos foram para o laboratório de informática da escola e durante essa etapa as professoras mediaram as pesquisas, auxilindo-os a acessar as informações na rede, depurá-las e selecionar quais eram relevantes para responder ao questionamento proposto no início e ao longo de sua pesquisa.

Durante a fase de depuração e ensaio foi discutido a finalidade de cada projeto com os alunos com o intuito de avaliar se o grupo deveria reelaborar seu planejamento de execução. Nessa discussão somente três grupos disseram que deveriam replanejar o projeto e justificaram de acordo com os depoimentos abaixo:

Nosso projeto até que estava ficando legal, mais aí descobrimos que a história que tínhamos lido era de um site que não tinha nada que indicava ser verdadeiro, aí tivemos que pesquisar em uma enciclopédia na biblioteca (Grupo 1).

Nossa parte do workshop é a solução para Bento Rodrigues, e fizemos uma planta baixa sobre o terreno e descobrimos que teríamos que trabalhar novamente, porque a

Samarco já pensou em como fazer a mesma que fizemos (Grupo 3). 
Eu queria falar dos metais, mas eles querem falar das doenças. Assim, vamos replanejar para falar das doenças (Grupo 4).

Este momento foi importante, pois é nesta etapa que o projeto fica com as características do grupo e para Nogueira (2008), a provocação do olhar crítico dos alunos em relação ao trabalho deve partir sempre do professor para a melhoria da qualidade e o aprofundamento do tema.

Os alunos foram questionados como gostariam de apresentar o resultado dos seus projetos. Todos escolheram apresenta-los em um workshop para toda a escola com apresentação de banners e assim, após o término das pesquisas, foram orientados como preparar um banner. Como estavam desenvolvendo um trabalho sobre questões ambientais, se preocuparam em confeccionar seus banners de maneira sustentável, utilizando o mínimo de materiais que não pudessem ser reciclados como papel Kraft, barbante, canetas e as duas imagens escolhidas pelo grupo, as quais foram as únicas impressas.

Após a finalização da produção dos banners, os alunos os apresentaram no pátio da escola para os demais colegas (Figura 1) (Fase de apresentação e avaliação). Durante a apresentação não podiam utilizar nenhuma "cola", pois a intenção era avaliar se eles construíram conhecimentos sobre seu tema de pesquisa, sua oralidade e como eles organizaram suas ideias.

Segundo Fernandes e Salgado (2020, p.1045) “ [...] o profissional precisa dominar não só as habilidades básicas de sua profissão, como também aquelas que lhe permitam organizar e transmitir informações e conhecimentos por meio da linguagem”. A apresentação dos banners foi uma oportunidade para observar essas habilidades.

No workshop, os colegas de outras classes foram passando pelos banners e os avaliando a partir de discussão com o grupo e do preenchimento da ficha apresentada no Quadro 3.

Cada grupo obteve 17 fichas de avaliação. Foram recebidas 372 fichas. Os resultados dessa avaliação mostraram que 289 fichas $(77,7 \%)$ avaliaram as apresentações e os banners como "Pleno", 56 fichas (15,05\%) como "Bom" e 27 (6,18\%) como "Satisfatório", apenas dois trabalhos (1,07\%) foram avaliados como "Insatisfatório". Esses resultados foram importantes para os grupos porque foi a primeira vez que apresentaram um trabalho para a escola, uma vez que estavam cursando o primeiro ano e não tinham intimidade com os colegas de outras classes.

$\mathrm{Na}$ aula seguinte os alunos responderam a um questionário para avaliar a Pedagogia de Projetos na compreensão das consequências socioambientais envolvidos em acidentes com barragens. Para essa análise os alunos responderam o questionário do Quadro 3. A primeira 
questão foi sobre o nível de interesse pelo trabalho, a maioria (92\%) respondeu que foi muito interessante. Para Nogueira (2008), esta resposta positiva é devido a escolha do tema pelos alunos. Para esse autor, isso leva a uma maior interação, podendo assim propiciar a contextualização e como consequência uma aprendizagem.

Sobre a dificuldade da realização dos projetos, 25 assinalaram que não acharam muito difícil trabalhar com projetos, 18 responderam ser extremamente difícil trabalhar com projetos, 15 responderam ser muito fácil, 12 às vezes difícil e 5 razoavelmente difícil. De acordo com Cohen e Lotan (2017), encontrar resposta correspondentes a estes extremos de fácil e difícil pode ser comum. Os que respondem extremamente difícil são aqueles alunos que sempre trabalharam com projetos montados por outra pessoa e assim, eles teriam apenas que executálo. Os que acreditam não ser muito difícil são aqueles que têm uma atitude mais proativa no grupo, e que provavelmente já trabalhou algumas vezes com projetos.

Quando os alunos foram questionados se sabiam exatamente a proposta do projeto (questão 3), 46 responderam que sabiam exatamente o que fazer, 24 responderam que no início não tinham entendido exatamente o que fazer, mas depois entenderam e 5 disseram nunca ficou claro sobre o que fazer.

A questão 4 solicitava que caso o aluno tivesse participado do desenvolvimento do projeto menos do que ele gostaria, que assinalasse o motivo. A maioria (58 alunos) assinalou que falou o quanto quis e isso demonstra a autonomia da pedagogia de projetos. Alguns resultados destoram do padrão, 2 alunos relataram que não tiveram chance de opinar no trabalho, outros 2 disseram que outra pessoa falou por ele e ainda outros 2 disseram que ninguém prestou atenção ao que falaram. Esses 6 alunos podem ser agrupados em "não participativos" e são lembrados por Cohen e Lotan (2017). Para esses autores, esse tipo de aluno será inserido em algum outro grupo e a própria equipe o vê como uma pessoa que não tem facilidade no trabalho em grupo.

As questões 5 e 6 foram analisadas juntas, pois questionavam sobre o trabalho em grupo. Embora os 6 alunos descritos acima tenham relatado que não foram ouvidos, nessas questões, eles e os outros alunos responderam que tiveram um bom entendimento com os membros do seu grupo.

Quando questionados se eles trabalhariam novamente com projetos apenas 2 alunos responderam que não gostariam. Os outros 73 alunos que disseram querer trabalhar novamente entenderam que não é tarefa fácil, mas que gostaram da experiência e que aprenderam mais do que se tivessem que apenas ouvir a explicação do professor. Os resultados dessa avaliação 
evidenciam que os alunos se envolveram com seus projetos e a maioria gostou de trabalhar com a pedagogia de projetos.

No mês de janeiro de 2019 houve um acidente envolvendo outra barragem, a da Mina Córrego do Feijão, localizada na cidade de Brumadinho (MG), com 250 mortos e 11 pessoas ainda estão desaparecidos.

Este acidente teve uma maior repercussão nas mídias, pois houve muitas vítimas, e ainda não pode ser mensurado o estrago ambiental que este acidente causou. Estima-se que o desastre ambiental do rompimento da barragem do Fundão seja o maior desastre ambiental que o Brasil já enfrentou, mas em número de mortos o da barragem do Feijão é o maior, e ambientalistas já esperam a contaminação do Rio São Francisco, uma das maiores bacias hidrográficas do país.

Como forma de avaliar a contribuição da pedagogia de projetos na compreensão socioambientais que envolveram esses acidentes realizou-se um outro questionário. Na primeira pergunta questionou-se se caso fosse o técnico da mineradora o que faria se soubesse das condições da barragem. Algumas respostas estão descritas a seguir:

Como técnico de edificações quando percebesse alguma anomalia tentaria reforçar estruturalmente a mesma e evacuaria a ara o mais rápido possível (Aluno $\mathrm{S}$ ).

Como técnico sabendo o tipo de barragem usada pela Vale iria se romper e causar muitos impactos ambientais, sociais e econômicos, não construiria esse tipo de barragem a montante se fosse engenheiro, mas como técnico, sabendo de tal perigo, como eles sabiam, avisaria a todos e evitaria que muitas vidas fossem perdidas (Aluna $\mathrm{N})$.

Com os laudos em mãos e a ciência de que brevemente a barragem a montante se romperia, tomaria decisões e adotaria métodos de prevenção ou até de sanar o acidente, como por exemplo filtrar parte do rejeito (Aluna $\mathrm{G}$ ).

A partir dessas e de outras respostas pode-se evidenciar como positiva a pedagogia de projetos em promover a conscientização socioambiental dos alunos, pois eles perceberam quanto é necessário para sua formação profissional.

Para Freire (2018), conscientizar-se é conquistar a realidade por meio de um ideal, desmitificar e haver uma ruptura com os conhecimentos prévios. Para esse autor, "não pode haver conscientização das pessoas sem uma denúncia radical das estruturas desumanizadoras, unida à proclamação de uma realidade nova que os homens podem criar” (p.1).

A questão 2 perguntava se após realizar seus projetos sobre acidentes com barragens, o aluno mudou seu olhar crítico sobre as questões que envolvem o meio ambiente na sua formação profissional. Foram entregues 75 questionários e todos responderam que sim. Algumas respostas estão descritas a seguir: 
Sim, muito pois vendo um exemplo de erro com muito impacto, fez com que buscássemos métodos mais eficazes para que acidentes como esse fossem evitados e ajudou a entender o que houve de errado (Aluno N).

Sim, para ficarmos cientes de que desastres ambientais podem acontecer a qualquer momento e que devesse prevenir evitando mortes e perdas do meio ambiente (Aluna M).

Sim, eu antes não tinha tanto conhecimento principalmente sobre o que a construção civil afeta o meio ambiente por muitos anos e não somente antes ou durante a construção, mas depois de décadas (Aluna C).

Essas respostas foram importantes porque de acordo com Sakr, Sherif e El-Haggar (2010) o ramo da construção civil é um dos setores econômicos que se apropria de diversos recursos naturais e se caracteriza por ampla ocupação e transformação da paisagem, causando danos expressivos ao meio ambiente e diversos impactos ambientais seja ele no consumo ou em descartes de bens. Desta forma, é importante que o técnico de edificações tenha consciência da relação da sua profissão com o meio ambiente.

$\mathrm{Na}$ última questão, os alunos responderam se como futuro profissional técnico, esses acidentes com barragens mudaram sua visão sobre sua responsabilidade técnica. Algumas respostas foram:

Me comove a sempre pensar e buscar meios sustentáveis para o meio ambiente e a construção civil, vendo tudo o que foi perdido e destruído por essa tragédia fez com que eu não quisesse que isso se repetisse, nunca mais. (Aluna $\mathrm{N}$ )

No sentido de responsabilidade e competência, pois uma edificação tem o intuito de abrigar vidas, não acabar com eles, por isso, desde já devemos pensar na segurança das pessoas e da edificação e nunca deixar de priorizar esta prática. (Aluno G)

Eu senti que poderia ter sido eu, que no futuro se eu cometer algum erro, poderei matar milhares de pessoas, e isso me comoveu muito e me deixou com bastante medo e certa da minha responsabilidade e com receio de como montar uma edificação. (Aluna B)

Pode-se observar que os alunos sentiram a responsabilidade de sua profissão, que ser um profissional técnico os remetem a cuidar do meio ambiente e do bem-estar da população. Essas respostas evidenciaram que a pedagogia de projetos auxiliou os alunos a aprimorarem as informações da mídia sobre os acidentes com barragens e a desenvolverem seu senso crítico em relação as questões que envolvem o técnico em edificações.

Os resultados apresentados nesse trabalho mostram que a pedagogia de projetos, embora não seja uma proposta recente, pode ser utilizada nos dias atuais como uma alternativa didática para qualquer área do conhecimento, uma vez que prioriza o processo investigativo em sala de aula, contribuindo assim para o desenvolvimento de competências e habilidades não só relacionadas as questões ambientais, mas também, dependendo da temática, para a aprendizagem de conceitos no componente curricular. 


\section{CONSIDERAÇÕES FINAIS}

A Pedagogia de Projeto foi utilizada neste trabalho com o objetivo investigar a sua contribuição na compreensão socioambiental envolvida em acidentes com barragens. Os resultados observados durante e após sua aplicação evidenciaram que este objetivo foi alcançado, pois passados 9 meses do término da sua aplicação houve outro acidente com barragens e os alunos foram questionados quanto a sua responsabilidade socioambiental como técnico de edificações e as respostas confirmaram este objetivo.

Evidenciou-se também que os alunos desenvolveram o gosto pela pesquisa pois se envolveram com seus projetos, distribuindo subtemas com seus colegas para desenvolver seus projetos.

\section{REFERÊNCIAS}

AGÊNCIA BRASIL. Com risco de rompimento de barragem, moradores deixam suas casas no ES. 2020. Disponível em: https://exame.com/brasil/com-risco-de-rompimento-debarragem-moradores-deixarem-suas-casas-no-es/. Acesso: Junho/2020.

ANTUNES, Celso. Projetos e práticas pedagógicas na educação infantil. Petrópolis, RJ: Vozes, 2012.

BENDER, Willian N. Aprendizagem Baseada em Projetos: educação diferenciada para o século XXI. Porto Alegre: Penso, 2014.

CARVALHO, Marllon Santos de; RIBEIRO, Kátia Daniela; MOREIRA, Raner Moacir; ALMEIDA, Alex Magalhães. Concentração de metais no rio Doce em Mariana, Minas Gerais, Brasil. Acta Brasiliensis, v. 1, n. 3, p.37-41, 2017.

CASTANHEIRA, Rhuann Patryk dos Santos; GUEDES, Flávio Leôncio; CASTRO JÚNIOR, Clênio Farias; ALMEDA, Kaylla Perreira; AZEVEDO, Flávia Garret. A viabilidade do uso de tecnologias sustentáveis na construção civil. Revista Eletronica da Estácio Recife, v.2, n.2, p.1-7, 2016. Disponível em: https://reer.emnuvens.com.br/reer/article/view/88. Acesso: $3 / 2020$

COHEN, Elizabeth G.; LOTAN, Rachel. A. Planejando o trabalho em grupo: estratégias para salas heterogêneas. Porto Alegre: Penso, 2017.

CONECTAS. Dados: o número da tragédia de Brumadinho. 2020. Disponível https://www.conectas.org/noticias/fact-sheets-o-numeros-da-tragedia-de-brumadinho. Acesso: Junho/2020.

COUTINHO, Clara Pereira. Metodologia de investigação em ciências sociais e humanas: Teoria e Prática. 2. ed. Coimbra: Edições Almedina, 2013.

CUNHA, Maíra Darido da; OLIVEIRA, Niviane Vieira Gois. Pedagogia de Projetos: a visão dos professores acerca do projeto de leitura no município de Bertioga - SP. Cadernos da Pedagogia, v. 13, n. 25, p. 4-15, Jul/Set 2019. 
FERNADES, Mirele Sanches; SALGADO, Tania Denise Miskinis. Estratégias docentes no desenvolvimento de competências em estudantes de um curso técnico em química. Revista Prática Docente. v. 5, n. 2, p. 1040-1056, mai/ago 2020.

FONTES, Roberta Neves; LOPES, Ivonete da Silva. As representações da mídia sobre o rompimento da barragem do Fundão em Mariana, Minas Gerais. Revista Espacios, v.38, n.34, p. 32-44, 2017.

FONSECA, Bruno. Brasil registra mais de três acidentes em barragens por ano. 2019 . Disponível em: https://apublica.org/2019/01/brasil-registra-mais-de-tres-acidentes-embarragens-por-ano/. Acesso: Set.2020

FREIRE, Paulo. Conscientização. São Paulo: Cortez, 2018.

GUEDES, José Demontier; SOUZA, Antonielle Serafim; SIDRIM, Francisca Maraysa Luciano; LIMA, Quenilda Fernandes de Oliveira. Pedagogia de Projetos: uma ferramenta para a aprendizagem. Revista Multidisciplinar e de Psicologia, v.10, n.33, Supl 2. p. 237-256, 2017.

HERNANDEZ, Fernández; VENTURA, Monteserrat. Organização do currículo por projetos de trabalho: o conhecimento é um caleidoscópio. Porto Alegre. Artes Médicas.1998.

MARTINS, José Santos. O trabalho com projetos de pesquisa: do ensino fundamental ao ensino médio. Campinas, SP: Papirus, 2001.

NOGUEIRA, Nilbo Ribeiro. Pedagogia dos projetos: etapas, papéis e atores. São Paulo, Ed. Érica, 2008.

OLIVEIRA, Ethel Silva de, GONZAGA, Amarildo Menezes. Pedagogia de Projetos: uma alternativa didática ao Ensino de Ciências. In VII ENCONTRO DE NACIONAL DE EDUCAÇÃO EM CIÊNCIAS, 7, 2009. Anais.......Belo Horizonte, 2009. p.1-13. Disponível em: http://www.nutes.ufrj.br/abrapec/viiienpec/resumos/R1540-1.pdf. Acesso: fevereiro/2020.

PAROLIN, Sonia Regina Hierro (Org.) MORAES, Deusdedit Carvalho de; OLIVEIRA, Heloisa Cortiani de; ZANON, Simone Luzia Maluf; NARDELLI, Thaise. Elaboração de projetos inovadores em educação profissional. Curitiba: Sesi/Senai/PR, 2006.

PAULA, Joaracy Lima de; HENRIQUE, Ana Lúcia Sarmento. Educação Ambiental na Educação Profissional: caminhando em direção à formação humana integral. Revista Ensino Interdisciplinar, Mossoró, v. 2, n. 05, p.83- 92, Jul., 2016.

PINHEIRO, Luciana Madsen. Pedagogia de Projetos: a metodologia que usa os sentidos e a arte como base para o aprendizado. Rio de Janeiro: Clube de Autores, 2016.

SAKR, Dalia A., SHERIF, Ahmed; EL-HAGGAR, Sahar Mohamed. Environmental management systems' awareness. Journal of cleaner production. v. 18, n.3, p. 210-218, 2010 . 
SANTOS, Dilce Melo; LEAL, Nadja Melo. A pedagogia de projetos e sua relevância como práxis pedagógica e instrumento de avaliação inovadora no processo de ensino aprendizagem. Revista Científica da FASETE, n. 19, p. 81-96, 2018.

SILVA, Maria Salete Cordeiro. A pedagogia de projetos no ensino de química: um relato de experiência. 2011, 63f. Dissertação (Mestrado em Ensino de Ciências e Matemática), Universidade Cruzeiro do Sul, São Paulo, 2011.

SILVA, Ricardo Bussons; BATISTA, Suelene da Silva; SILVA, Marinaldo Felipe. Metodologia de projetos no ensino básico e tecnológico: uma educacão emancipadora. Educação pública, v.17, ed. 24, p.1, 2017.

Recebido em: 14 de julho de 2020.

Aprovado em: 14 de outubro de 2020. 